\title{
Calculation Method for Evaluation \\ of Solid Fuels Net Calorific Values \\ on the Basis of Technical Analysis
}

\author{
Nikolay A. Yazykov*, \\ Alexandr D. Simonov and Vadim A. Yakovlev \\ Borescov Institute of Catalysis $S B R A S$ \\ 5 Lavrentiev, Novosibirsk, 630090, Russia
}

Received 02.01.2018, received in revised form 07.02.2018, accepted 18.03.2018

\begin{abstract}
In the work the calculation method to define solid fuels net calorific values of woody biomass, peat, lignite, coal and anthracite on the basis of technical analysis, including the determination of total moisture content, ash content and yield of volatile substances, was developed. The method includes determining atomic relations of hydrogen to carbon and oxygen to carbon with subsequent estimation of elemental composition of the combustible matter and raw matter of solid fuels. Three variants for calculating relations of hydrogen to carbon and oxygen to carbon were considered. For sulfur content in solid fuels combustible matter less than $2 \% \mathrm{wt}$. the standard deviation of estimated solid fuels net calorific values from literature data was 3.0 $\div 3.4 \%$ depending on the relations of hydrogen to carbon and oxygen to carbon calculation variant. For sulfur content in solid fuels combustible matter of $2.1 \div 8.4 \% \mathrm{wt}$. the standard deviation of estimated solid fuels net calorific values from literature data was $4.7 \div 5.6 \%$. Such way of the using the technical analysis data to determine net calorific values of solid fuels may be useful in the absence of the elemental composition and solid fuels net calorific values, as well as to control characteristics of solid fuels in boilers.
\end{abstract}

Keywords: wood biomass, peat, coal, anthracite, relations of hydrogen to carbon and oxygen to carbon, net calorific value.

Citation: Yazykov N.A., Simonov A.D., Yakovlev V.A. Calculation method for evaluation of solid fuels net calorific values on the basis of technical analysis, J. Sib. Fed. Univ. Chem., 2018, 11(1), 93-109. DOI: 10.17516/1998-2836-0061.

(c) Siberian Federal University. All rights reserved

* Corresponding author E-mail address: yazykov@catalysis.ru 


\title{
Расчетный метод оценки низшей теплоты сгорания твердых топлив \\ на основе данных технического анализа
}

\author{
Н.А. Языков, А.Д. Симонов, В.А. Яковлев \\ Институт катализа им. Г.К. Борескова СО РАН \\ Россия, 630090, Новосибирск, пр. Академика Лаврентьева, 5
}

В работе разработан расчетный метод определения низшей теплоты сгорания древесной биомассы, торфа, бурых углей, каменных углей и антрацита на основе данных технического анализа, включающих определение содержания общей влаги, зольности и выхода летучих веществ. Расчетный метод включает определение атомных отношений водорода к углероду и кислорода к углероду с последующим определением элементного состава горючей массы, рабочей массы твердого топлива. Предложено три варианта расчета отношений водорода $\kappa$ углероду и кислорода к углероду. В зависимости от варианта расчета отношений водорода к углероду и кислорода к углероду среднеквадратичное отклонение низшей теплоты сгорания твердых топлив от литературных данных при содержании серы в горючей массе твердых

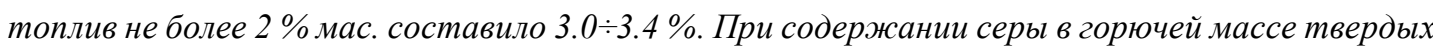

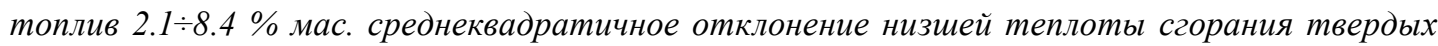
топлив от литературных данных составило 4.7-5.6\%. Такой подход с использованием данных технического анализа для определения низщей теплоты сгорания твердых топлив может быть полезен в случае отсутствия данных по элементному составу и низшей теплоты сгорания твердого топлива, а также для контроля характеристик твердого топлива в котельных по месту.

Ключевые слова: древесная биомасса, торф, уголь, антрацит, отношение водорода к углероду, отночение кислорода к углероду, низшая теплота сгорания.

\section{Введение}

В Институте катализа СО РАН разработана технология каталитического сжигания газообразных, жидких и твердых топлив в кипящем слое [1-3], которая основана на совмещении тепловыделения и теплоотвода в едином кипящем слое. Присутствие катализатора позволяет снизить температуру сжигания органического топлива до $350-750{ }^{\circ} \mathrm{C}$ в зависимости от катализатора и, соответственно, снизить выбросы вредных веществ по сравнению с факельным сжиганием и сжиганием топлив в кипящем слое инертного материала. В качестве твердого топлива могут быть использованы древесная биомасса, торф, бурый уголь, каменный уголь. На основе этой технологии был создан ряд каталитических котельных, работающих на бурых и каменных углях Кузбасского бассейна, на углях Читинской области, в которых сжигание происходит при температуре $750{ }^{\circ} \mathrm{C}$. Практический опыт эксплуатации таких котельных показал, что уголь, поставляемый периодически, может иметь различный элементный состав. В зависимости от условий и длительности хранения угля в котельных состав угля меняется за 
счет, например, изменения влажности. Кроме этого, при отгрузке угля с грунта возможно попадание глины и т.п., что также изменяет характеристики угля. Некоторые котельные находятся в отдаленных регионах, в результате чего нет возможности быстрого проведения анализов для определения характеристик топлива. В связи с этим представляет интерес разработка метода оценки характеристик топлива по месту. Таким методом может быть использование для этого данных технического анализа.

Теплоту сгорания определяют в калориметрической бомбе и на основе полученных результатов проводят пересчет в высшую и низшую теплоту сгорания рабочей массы твердого топлива $[6,7]$. При отсутствии данных по теплоте сгорания твердого топлива на основе информации по элементному составу горючей массы твердого топлива высшую теплоту сгорания можно определить по формуле Д.И. Менделеева [8]

$$
Q_{s}{ }^{d a f}=81 C^{d a f}+300 H^{d a f}-26\left(O^{d a f}-S^{d a f}\right),
$$

где $Q_{s}^{d a f}$ - высшая теплота сгорания горючей массы, ккал/кг; $C^{d a f}$ - содержание углерода в горючей массе твердого топлива, \%; $H^{d a f}$ - содержание водорода в горючей массе твердого топлива, \%; $O^{d a f}$ - содержание кислорода в горючей массе твердого топлива, $\% ; S^{d a f}$ - содержание серы в горючей массе твердого топлива, \%.

Для определения низшей теплоты сгорания с учетом теплоты испарения воды, образующейся при сгорании водорода и содержащейся в топливе общей влаги $W_{t}^{r}$, зольности $A^{r}$ рабочей массы твердого топлива формула имеет вид [9]

$$
Q_{i}^{r}=81 C^{r}+246 H^{r}-26\left(O^{r}-S^{r}\right)-6 W_{t}^{r},
$$

где $Q_{i}^{r}-$ низшая теплота сгорания топлива, ккал/кг; $C^{r}$ - содержание углерода в рабочей массе твердого топлива, \%; $H^{r}$ - содержание водорода в рабочей массе твердого топлива, \%; $O^{r}-$ coдержание кислорода в рабочей массе твердого топлива, \%; $S^{r}$ - содержание серы в рабочей массе твердого топлива, \%.

Для расчета теплоты сгорания по данным элементного состава можно также использовать другие формулы. В работах $[9,10]$ приведены обзоры по формулам расчета теплоты сгорания углей и других твердых топлив, полученные разными авторами. В работе [11] приведены формулы расчета теплоты сгорания для углей месторождений Сибири и Дальнего Востока.

В процессе пиролиза при определении выхода летучих веществ твердых топлив основная часть водорода, кислорода, азота и неароматического углерода, входящего в состав горючей массы твердого топлива, переходит в газовую фазу и образуется коксовый остаток [10]. Выход летучих веществ $V^{d a f}$ определяется числом периферийных атомов ароматического углерода, степенью замещенности ароматических кластеров, количеством водорода в алифатических группах и содержанием кислорода $[10,14]$. Соответственно, при увеличении степени метаморфизма углей повышается степень ароматичности и наблюдается снижение выхода летучих веществ $[6,10]$. Изменение структуры углей при изменении степени метаморфизма отражено в обобщенной модели структуры органической массы углей [12]. В работах $[13,14]$ приведены обзоры по другим моделям структуры угля, которые также отражают изменение структуры угля с увеличением содержания углерода. 
В работе [15] отмечается, что знание элементного состава твердых топлив позволяет определить количество летучих веществ, которое может быть выражено через атомные отношения элементов в горючей массе углей $\left(H_{a t} / C_{a t}\right)$ и $\left(O_{a t} / C_{a t}\right)$. Также возможно определение выхода летучих веществ непосредственно из данных по элементному составу горючей массы углей $[10$, 11]. Таким образом существует взаимосвязь между элементным составом горючей массы твердого топлива и выходом летучих веществ. В связи с этим возможно решение обратной задачи: определение элементного состава горючей массы твердых топлив на основе данных по выходу летучих веществ с последующим определением низшей теплоты сгорания твердого топлива с учетом содержания общей влаги и зольности. Такой подход может быть полезен в случае отсутствия данных по элементному составу и низшей теплоты сгорания твердого топлива и для контроля характеристик сжигаемого твердого топлива.

Ископаемые твердые топлива имеют органическое происхождение $[6,10,16]$. Образование бурых и каменных углей может происходить как из исходных органических веществ, так и через стадию образования торфа: исходные органические вещества $\rightarrow$ торф $\rightarrow$ бурый уголь $\rightarrow$ каменный уголь $\rightarrow$ антрацит $\rightarrow$ графит $[6,16]$.

По классификации горючих ископаемых (каустобиолитов) А.Ф. Добрянского, построенной по соотношению основных органогенных элементов (углерода и водорода), выделено два направления изменения в природных условиях исходного органического материала по мере возрастания содержания углерода:

1) сапропель, кероген сланцев, окисленные асфальты, смолистые, метановые и смолистые нефти;

2) древесина, торф, бурый уголь, каменный уголь, антрацит.

Первое направление характеризуется увеличением содержания водорода при увеличении содержания углерода, второе направление характеризуется уменьшением содержания водорода при увеличении содержания углерода. Соответственно, следует ожидать, что выход летучих веществ твердых топлив в первом направлении с ростом содержания водорода и углерода должен увеличиваться, в то время как для твердых топлив во втором направлении по мере увеличения содержания углерода и уменьшения содержания водорода выход летучих веществ должен уменьшаться. Классификация А.Ф. Добрянского приведена в работах $[6,17]$.

Учитывая вышесказанное, целью данной работы была разработка расчетного метода оценки элементного состава горючей массы твердого топлива и низшей теплоты сгорания древесины, торфа, бурого угля, каменного угля, антрацита на основе технического анализа.

\section{Взаимосвязь структурного параметра $Z$, характеризующего конденсированность горючей массы твердых топлив, с выходом летучих веществ $V^{\text {taf }}$}

Для разработки расчетного метода использовали данные Всероссийского теплотехнического института (ВТИ) по составу и результатам технического анализа твердых топлив, приведенные в работе [18], что отражено в табл. 1, 2. Основные критерии выбора данных по составу твердых топлив: твердые топлива по мере увеличения содержания углерода, начиная от древесины до антрацитов; твердые топлива с широким диапазоном значения низшей теплоты

$$
-96-
$$


Таблица 1. Элементный состав, результаты технического анализа и низшая теплота сгорания углей разной степени метаморфизма с содержанием серы менее 2 \% мас., торфа и древесной биомассы, по данным ВТИ, приведенным в работе [18]

Table 1. Elemental composition, results of the technical analysis and net calorific values of coals of different metamorphism grade with sulfur content less than $2 \%$ wt., peat and woody biomass according VTI data given in $[18]$

\begin{tabular}{|c|c|c|c|c|c|c|c|c|c|c|}
\hline Месторождение & $\begin{array}{l}\underset{\mathscr{u}}{0} \\
\stackrel{\Xi}{\Sigma}\end{array}$ & $\begin{array}{l}0^{\circ} \\
\stackrel{2}{=}\end{array}$ & $\begin{array}{l}\partial^{\circ} \\
\nabla^{\circ}\end{array}$ & $\begin{array}{l}d^{\circ} \\
\text { है }\end{array}$ & $\frac{\partial^{\circ}}{\Xi^{n}}$ & 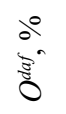 & $\begin{array}{l}\partial^{\circ} \\
\vec{z}^{\circ}\end{array}$ & 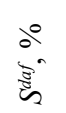 & $\begin{array}{l}\partial^{\circ} \\
\stackrel{\Xi}{\Delta}\end{array}$ & $\approx \tilde{\sigma}$ \\
\hline Донецкий бассейн & A & 4.0 & 6.0 & 94.0 & 1.8 & 1.3 & 1.0 & 1.9 & 4.0 & 7240 \\
\hline Донецкий бассейн & A & 5.0 & 14.0 & 93.5 & 1.8 & 1.7 & 1.0 & 2.0 & 4.0 & 6475 \\
\hline Егоршинское (Урал) & A & 5.0 & 23.0 & 90.0 & 3.6 & 4.5 & 1.8 & 0.6 & 9.0 & 5810 \\
\hline Октябрьское (Сахалин) & $\mathrm{T}$ & 6.0 & 7.0 & 90.0 & 4.5 & 3.0 & 2.0 & 0.5 & 18.0 & 7340 \\
\hline Прокопьевское (Кузбасс) & $\mathrm{CC}$ & 7.0 & 12.0 & 89.0 & 4.2 & 4.1 & 2.2 & 0.5 & 14.0 & 6590 \\
\hline Киселевское (Кузбасс) & $\mathrm{CC}$ & 8.0 & 10.0 & 88.0 & 4.5 & 4.7 & 2.3 & 0.5 & 21.0 & 6650 \\
\hline Октябрьское (Сахалин) & K & 4.0 & 12.0 & 88.0 & 5.1 & 4.4 & 2.0 & 0.5 & 23.0 & 7040 \\
\hline Прокопьевское (Кузбасс) & $\mathrm{CC}$ & 8.5 & 12.0 & 87.0 & 5.0 & 5.2 & 2.2 & 0.6 & 24.0 & 6510 \\
\hline Кемеровское (Кузбасс) & $\mathrm{CC}$ & 9.0 & 16.0 & 86.0 & 5.0 & 6.3 & 2.0 & 0.7 & 26.0 & 6060 \\
\hline Карагандинский бассейн & Ж & 7.5 & 27.0 & 85.0 & 5.1 & 7.3 & 1.4 & 1.2 & 28.0 & 5355 \\
\hline Воркутинское (Печорский бассейн) & Ж & 8.0 & 23.0 & 85.0 & 5.3 & 6.2 & 2.2 & 1.3 & 30.0 & 5670 \\
\hline Киселевское (Кузбасс) & $\mathrm{CC}$ & 9.0 & 9.0 & 83.0 & 5.2 & 9.3 & 2.0 & 0.5 & 33.0 & 6410 \\
\hline Букачачинское (Читинская обл.) & $\Gamma$ & 8.0 & 10.0 & 82.0 & 5.5 & 10.7 & 1.1 & 0.7 & 38.0 & 6350 \\
\hline Баланашское (Урал) & $\Gamma$ & 11.0 & 24.0 & 80.5 & 5.5 & 11.2 & 1.5 & 1.3 & 40.0 & 5110 \\
\hline Ленинское (Кузбасс) & Д & 10.0 & 5.5 & 79.0 & 5.5 & 12.6 & 2.4 & 0.5 & 40.0 & 6300 \\
\hline Минусинское Хакасский АО & Д & 13.0 & 12.0 & 78.0 & 5.5 & 13.6 & 2.2 & 0.7 & 42.0 & 5570 \\
\hline Букачачинское (Читинская обл.) & Д & 12.0 & 12.0 & 78.0 & 5.5 & 14.7 & 1.1 & 0.7 & 42.0 & 5560 \\
\hline Черемховское (Иркутская обл.) & Д & 12.0 & 17.0 & 78.0 & 5.7 & 13.3 & 1.0 & 1.4 & 45.0 & 5330 \\
\hline Черновское (Читинская обл.) & Б & 33.0 & 11.0 & 75.0 & 5.0 & 17.9 & 1.3 & 0.8 & 42.0 & 3920 \\
\hline Тарбагатайское (Читинская обл.) & Б & 25.0 & 15.0 & 74.0 & 5.1 & 18.1 & 1.3 & 1.5 & 43.0 & 4200 \\
\hline Сахалин Юг & Б & 18.0 & 15.0 & 73.0 & 5.6 & 19.7 & 1.4 & 0.3 & 50.0 & 4520 \\
\hline Мукачевское (Украина) & Б & 45.0 & 45.0 & 65.0 & 5.8 & 27.0 & 1.0 & 1.2 & 60.0 & 1500 \\
\hline Торф кусковой & & 40.0 & 11.0 & 57.8 & 6.0 & 33.4 & 2.5 & 0.3 & 70.0 & 2560 \\
\hline Древесная биомасса & & 40.0 & 1.0 & 51.0 & 6.1 & 42.3 & 0.6 & нет & 85.0 & 2440 \\
\hline
\end{tabular}

Обозначения: А - антрацит; Т - тощий уголь; СС - слабоспекающийся уголь: К - коксовый уголь; Ж - жирный уголь; Г - газовый уголь; Д - длиннопламенный уголь; Б - бурый уголь.

Таблица 2. Элементный состав, результаты технического анализа и низшая теплота сгорания продуктов термической переработки углей и древесины, по данным ВТИ, приведенным в работе [18]

Table 2. Elemental composition, results of the technical analysis and net calorific values of coal and wood thermal processing products according to the VTI data given in [18]

\begin{tabular}{|c|c|c|c|c|c|c|c|c|c|}
\hline Твердое топливо & $W_{t}^{r}, \%$ & $A^{d}, \%$ & $C^{\text {daf }}, \%$ & $H^{\text {daf }}, \%$ & $O^{\text {daf }}, \%$ & $N^{\text {daf }}, \%$ & $S^{\text {daf }}, \%$ & $V^{\text {daf }}, \%$ & $Q_{i}^{r}$, ккал/кг \\
\hline Кокс (25 мм) & 4.0 & 11.0 & 96.5 & 0.4 & 0.9 & 1.2 & 1.0 & 1.0 & 6640 \\
\hline Коксовая мелочь & 18.0 & 20.0 & 92.0 & 2.0 & 2.9 & 1.5 & 1.6 & 8.0 & 5040 \\
\hline Древесный уголь & 6.0 & 3.0 & 88.0 & 3.5 & 7.9 & 0.4 & 0.2 & 15.0 & 7090 \\
\hline
\end{tabular}


сгорания, в данном случае от 1500 до 7340 ккал/кг; твердые топлива с содержанием серы менее 2 \% мас. для уменьшения ошибки при расчете низшей теплоты сгорания.

Взаимосвязи между структурными параметрами и показателями углей можно описать в рамках аддитивной модели $[10,13,19]$. Для получения различных взаимосвязей используют величины $n_{a m}$ (количество атомов в единице органической массы) и $n_{c \varepsilon}$ (количество связей в единице органической массы) [20]. Такой подход позволяет на основе данных по элементному составу получить, например, взаимосвязь структурного параметра $\delta$, характеризующего степень ненасыщенности органической массы топлив, и $n_{a m} / n_{C}$, где $n_{C}-$ количество атомов углерода в единице органической массы [20]. Взаимосвязь этих параметров дает возможность построить единую классификацию горючих ископаемых. Также возможно определение содержания ароматического и алифатического углерода для углей разной степени метаморфизма [21].

В данной работе в качестве характеристики конденсированности органической массы использовали параметр

$$
Z=2 n_{c \varepsilon} / n_{a m}
$$

В случае полностью конденсированной системы в виде графита, представляющей только углерод, $Z=4$, что соответствует количеству связей, которые образует углерод. Уменьшение этого параметра происходит в случае присутствия в системе элементов с валентностью меньше 4.

На рис. 1 показана зависимость параметра $Z$ горючей массы твердых топлив, включая древесную биомассу, торф и угли разной степени метаморфизма, от выхода летучих веществ $V^{\text {daf }}$. Для построения этой зависимости использовали литературные данные по элементному составу твердых топлив [18], приведенные в табл. 1, 2. Данные элементного состава горючей массы торфа в табл. 1 близок к среднему составу. Например, по данным работы [6], элементный состав торфов меняется в следующих пределах ( \% мас.): $C^{d a f}-54.5 \div 61.9, H^{d a f}-5.1 \div 6.2$,

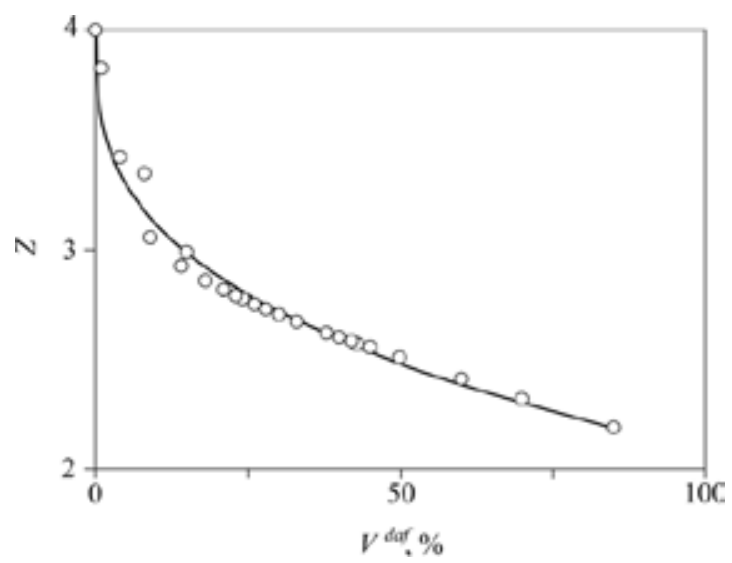

Рис. 1. Зависимость параметра $Z$ горючей массы твердых топлив от выхода летучих веществ $V^{d a f}$. Точки значения, полученные по формуле (3) с использованием литературных данных [18] по элементному составу твердых топлив и выходу летучих веществ, линия - значения, полученные по формуле (4)

Fig. 1. The solid fuel combustible matter parameter $Z$ dependence of the yield of volatile substances $V^{\text {daf }}$. Points values obtained by formula (3) using literature data [18] of the elemental composition of solid fuels and the yield volatile substances, line - values obtained by the formula (4) 
$N^{d a f}-1.9 \div 2.8, O^{d a f}+S^{d a f}-30.9 \div 34.0$. Древесная биомасса, состав которой раскрыт в табл. 1 , также близка к среднему составу. В работе [22] с тем же самым элементным составом горючей массы эта древесная биомасса обозначена как кородревесная биомасса без конкретизации какой породы древесина. В работе [23] отмечено, что элементный состав и теплота сгорания различных видов растительной биомассы достаточно близки, приведен следующий состав сухой древесины ( \% мас.): $C^{d}-47 \div 51 ; H^{d}-5.7 \div 6.3 ; O^{d}-39 \div 44 ; N^{d}-0.13 \div 0.54, A^{d}-0.5 \div 4$, что соответствует использованным данным по составу древесины, отраженным в табл. 1. В работе [24] также отмечается, что элементный состав органической части древесины у различных древесных пород практически одинаков ( \% мас.): $C^{d a f}-49 \div 50 ; H^{d a f} \sim 6 ; O^{d a f}-43 \div 44 ; N^{d a f}-0.1 \div 0.3$.

Зависимость параметра $Z$ от выхода летучих веществ может быть выражена формулой

$$
Z=4-0.413\left(V^{d a f}\right)^{1 / 3},
$$

где $V^{\text {daf }}$ в мас. \%.

Определение величины 0.413 проводили методом последовательных приближений для достижения мининального среднеквадратичного отклонения рассчитанных значений $Z$ по формуле (4) от рассчитанных значений по формуле (3). При определении параметра $Z$ по формуле (4) по данным выхода летучих веществ $V^{\text {daf }}$ среднеквардатичное отклонение от рассчитанных значений по формуле (3) по данным элементного состава горючей массы составило $2.3 \%$.

Полученная формула (4) может быть преобразована для решения обратной задачи оценки выхода летучих веществ при наличии данных по элементному составу горючей массы твердого топлива, исходя из которых можно рассчитать параметр Z. Формула для оценки выхода летучих веществ имеет вид

$$
V^{\text {daf }}=((4-Z) / 0.413)^{3} .
$$

На рис. 2 показано отклонение расчетных значений выхода летучих веществ по формуле (5) от литературных данных [18].

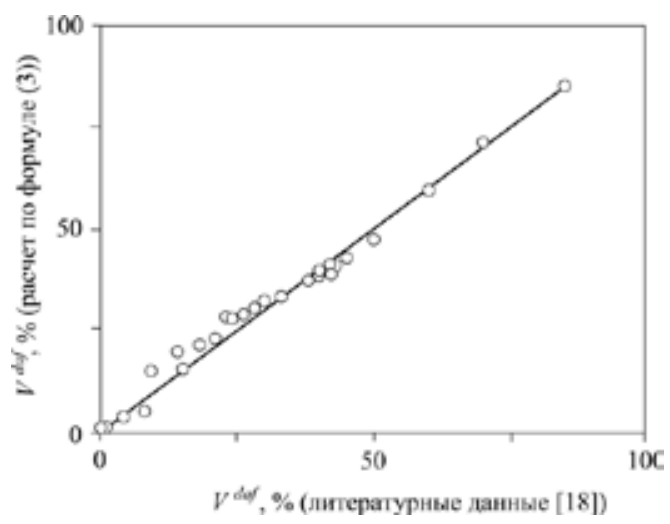

Рис. 2. Отклонение рассчитанных по формуле (5) значений выхода летучих веществ (точки) $V^{\text {taf }}$ от литературных данных [18] (линия)

Fig. 2. The deviation of the calculated values of the yield volatile substances $V^{\text {daf }}$ (points) according to the formula (5) from literature data [18] (line) 


\section{Взаимосвязь параметра $Z$ \\ и структурными параметрами $\left(H_{a t} / C_{a t}\right)$ и $\left(O_{a t} / C_{a t}\right)$}

Вариант 1. Элементами, входящими в состав горючей массы твердых топлив, являются углерод, кислород, водород, азот и сера. Большое количество элементов в составе горючей массе твердых топлив затрудняет вывод зависимостей $\left(H_{a t} / C_{a t}\right)$ и $\left(H_{a t} / C_{a t}\right)$ от $Z$. Учитывая, что основная горючая масса состоит из углерода, кислорода и водорода, можно упростить решение задачи нахождения зависимостей $\left(H_{a t} / C_{a t}\right)$ и $\left(O_{a t} / C_{a t}\right)$ от $Z$. На рис. 3 показано соотношение между параметром $Z_{C H O}$, рассчитанным только по содержанию углерода, водорода и кислорода, и параметром $Z$, рассчитанным с учетом всех элементов горючей массы твердого топлива.

На рис. 3 видно, что значения параметра $Z$ для твердых топлив, рассчитанные по всем элементам в горючей массе, практически совпадают с рассчитанными только с учетом содержания углерода, водорода и кислорода $Z_{\text {сно }}$. Поэтому в дальнейшем было использовано более простое выражение

$$
Z=\left(4 n_{C}+2 n_{O}+n_{H}\right) /\left(n_{C}+n_{O}+n_{H}\right)
$$

где $n_{C}, n_{O}, n_{H}$ - количество атомов углерода, кислорода и водорода в единице горючей массы соответственно.

При делении числителя и знаменателя на $n_{C}$ получаем выражение:

$$
Z=\left(4+2\left(O_{a t} / C_{a t}\right)+\left(H_{a t} / C_{a t}\right)\right) /\left(1+\left(O_{a t} / C_{a t}\right)+\left(H_{a t} / C_{a t}\right)\right)
$$

Применяя выражение

$$
Z_{H O}=\left(2\left(O_{a t} / C_{a t}\right)+\left(H_{a t} / \mathrm{C}_{\mathrm{at}}\right)\right) /\left(\left(O_{a t} / C_{a t}\right)+\left(H_{a t} / C_{a t}\right)\right) \text {, }
$$

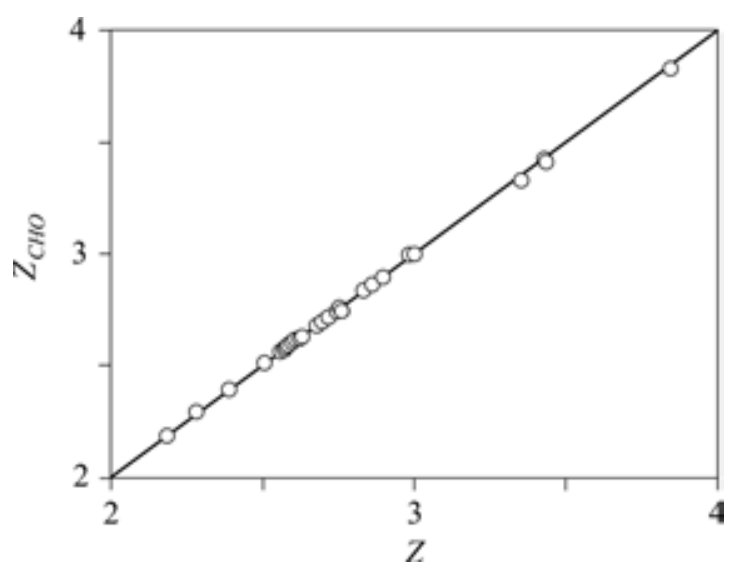

Рис. 3. Соотношение параметра $Z$, рассчитанного с учетом всех элементов, входящих в состав горючей массы, и рассчитанного только с учетом содержания углерода, водорода и кислорода $Z_{C H O}$ по данным [18]

Fig. 3. The ratio of the parameter $Z$ calculated taking into account all the elements included in the composition of the combustible matter and calculated only with regard to the content of carbon, hydrogen and oxygen $Z_{C H O}$ according [18] 
после подстановки формулы (8) в формулу (7) и преобразований получаем формулу для расчета атомного отношения водорода к углероду

$$
\left(H_{a t} / C_{a t}\right)=(4-Z)\left(2-Z_{H O}\right) /\left(Z-Z_{H O}\right) \text {, }
$$

а также формулу для расчета атомного отношения кислорода к углероду

$$
\left(O_{a t} / C_{a t}\right)=\left(H_{a t} / C_{a t}\right)\left(Z_{H O}-1\right) /\left(2-Z_{H O}\right) .
$$

Из полученных формул (9) и (10) следует, что между отношениями $\left(O_{a t} / C_{a t}\right)$ и $\left(H_{a t} / C_{a t}\right)$ существует взаимосвязь. Параметр $Z_{H O}$ характеризует соотношение кислорода и водорода в горючей массе твердых топлив, при этом $1<Z_{H O}<2$.

Для определения $\left(H_{a t} / C_{a t}\right)$ и $\left(O_{a t} / C_{a t}\right)$ по формулам (9) и (10) необходимо знать значение $Z_{H O}$. На рис. 4 показана зависимость $Z_{H O}$ от $V^{d a f}$. Для определения $Z_{H O}$ в данной работе предложена зависимость от $V^{d a f}$, которая имеет следующее выражение:

$$
Z_{H O}=1+0.00355 V^{\text {daf }} \text {. }
$$

На рис. 4 видно, что для твердых ископаемых топлив, включая торф и древесную биомассу, наблюдается линейная корреляция между $Z_{H O}$ и выходом летучих веществ $V^{d a f}$. Наибольшее отклонение наблюдается для продуктов термической переработки твердых топлив (кокс, древесный уголь). Значения $Z_{H O}$ в этих случаях соответствуют каменным углям, что указывает на присутствие в этих продуктах фрагментов исходного сырья, содержащих кислород и водород. В конечном итоге при использовании формулы (11) это приводит к завышению содержания водорода, имеющего наибольший коэффициент в формуле Д.И. Менделеева, и, соответственно, к завышению величины низшей теплоты сгорания в пределах $4.2 \div 5.1 \%$.

Вариант 2. Другой метод преобразования формулы (6) получен при использовании выражения

$$
1+\left(O_{a t} / C_{a t}\right)+\left(H_{a t} / C_{a t}\right)=b
$$

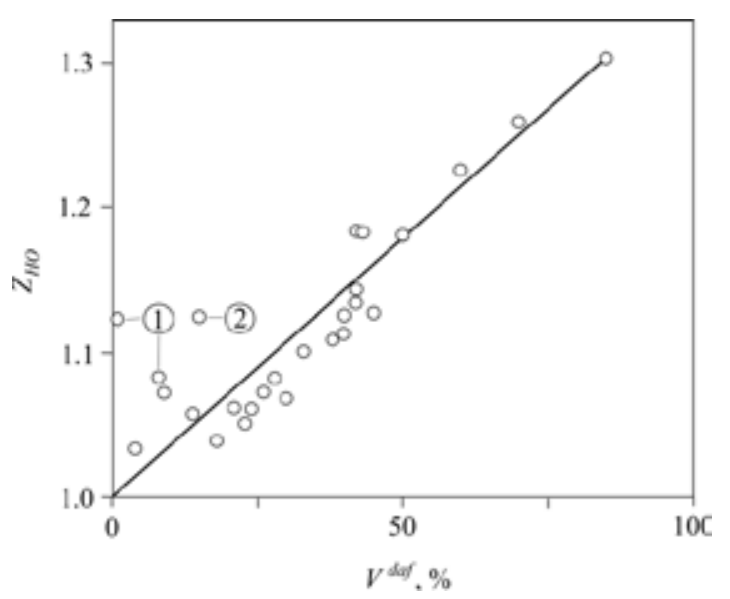

Рис. 4. Зависимость параметра $Z_{\text {но }}$ от выхода летучих веществ $V^{d a f} .1$ - кокс, 2 - древесный уголь

Fig. 4. The parameter $Z_{H O}$ dependence of the yield of volatile substances $V^{\text {daf }} .1$ - coke, 2 - charcoal 
Соответственно, формула для определения параметра $Z$ после подстановки в формулу (7) имеет вид

$$
Z=\left(3+b+\left(O_{a t} / C_{a t}\right)\right) / b=\left(2+2 b-\left(H_{a t} / C_{a t}\right)\right) / b .
$$

Исходя из формулы (12), доля атомов углерода в системе на единицу горючей массы $\alpha_{C}=1 / b$. На основе формулы (13) после подстановки $\alpha_{C}=1 / b$ получены следующие зависимости атомных отношений кислорода и водорода к углероду, отражающие взаимосвязь с долей атомов углерода в системе и параметром $Z$ :

$$
\begin{aligned}
& \left(H_{a t} / C_{a t}\right)=2-(Z-2) / \alpha_{C}, \\
& \left(O_{a t} / C_{a t}\right)=\left((Z-1) / \alpha_{C}\right)-3 .
\end{aligned}
$$

Для применения этих формул необходимо знание величины $\alpha_{C}$. В данной работе предложена достаточно простая эмпирическая формула

$$
\alpha_{C}=1-0.775 f_{z}^{0.75}, f_{z}=(4-Z) / Z .
$$

На рис. 5 показаны значения $\alpha_{C}$, полученные на основе литературных данных [18] и рассчитанные по формуле (16).

Вариант 3. Так же можно определить значение структурных параметров $\left(H_{a t} / C_{a t}\right)$ и $\left(O_{a t} / C_{a t}\right)$ по эмпирическим формулам как функции от $f_{z}=(4-Z) / Z$ :

$$
\begin{aligned}
& \left(H_{a t} / C_{a t}\right)=1.796 f_{z}^{1.2}, \\
& \left(O_{a t} / C_{a t}\right)=f_{z}^{n}, n=4.65-2.5 f_{z} .
\end{aligned}
$$

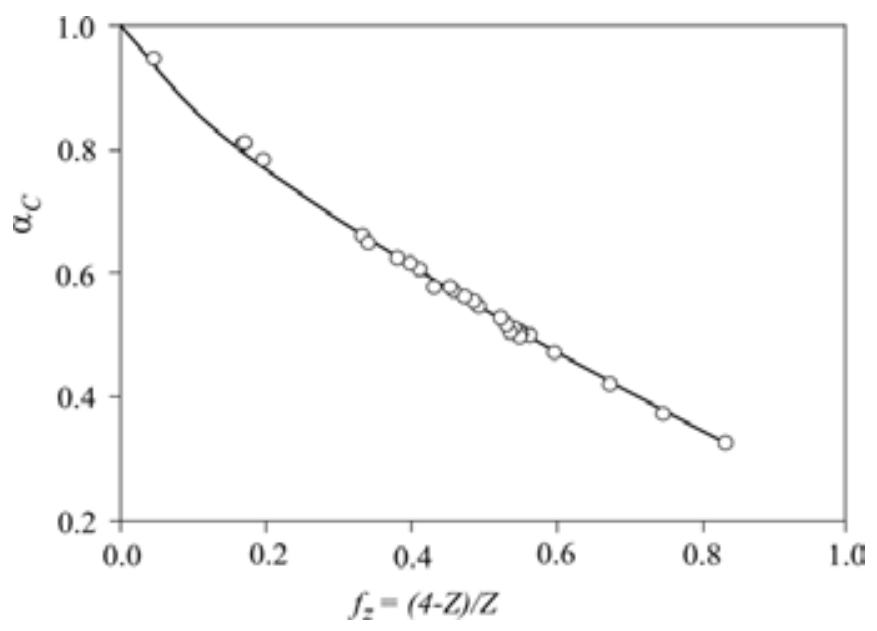

Рис. 5. Значения $\alpha_{C}$, полученные на основе литературных данных [18] (точки) и рассчитанные (линия) по формуле (16)

Fig. 5. Values of $\alpha_{C}$ obtained on the basis of literature data [18] (points) and calculated (line) according to the formula (16) 


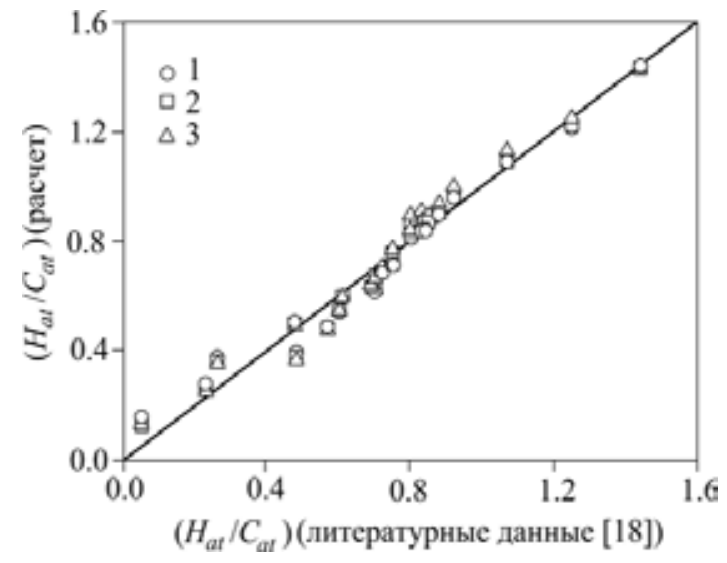

A

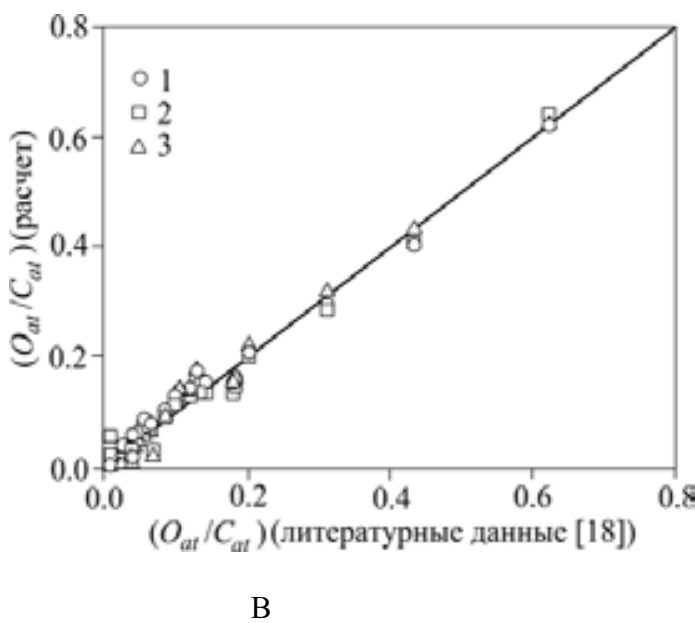

B

Рис. 6. Соотношение структурных параметров $\left(H_{a t} / C_{a t}\right)-\mathbf{A}$ и $\left(O_{a t} / C_{a t}\right)-\mathbf{B}$ определенных по литературным данным элементного состава горючей массы твердых топлив [18] и рассчитанных по различным вариантам: 1 - вариант 1; 2 - вариант 2; 3 - вариант 3

Fig. 6. The ratio of the structural parameters $\left(H_{a t} / C_{a t}\right)-\mathbf{A}$ и $\left(O_{a t} / C_{a t}\right)-\mathbf{B}$ defined according to literature data [18] for the elemental composition of the combustible matter of solid fuels and calculated according to different variants: 1 - variant $1 ; 2$ - variant $2 ; 3$ - variant 3

На рис. 6 показано соотношение структурных параметров $\left(H_{a t} / C_{a t}\right)$ и $\left(O_{a t} / C_{a t}\right)$, определенных по литературным данным элементного состава горючей массы твердых топлив и рассчитанных по разным вариантам.

Из полученных результатов следует, что все варианты позволяют оценить $\left(H_{a t} / C_{a t}\right)$ и $\left(O_{a t} / C_{a t}\right)$ в горючей массе твердых топлив.

\section{Определение элементного состава горючей массы твердых топлив и их низшей теплоты сгорания}

На основе полученных атомных отношений $\left(H_{a t} / C_{a t}\right)$ и $\left(O_{a t} / C_{a t}\right)$ с учетом относительных атомных масс элементов было определено процентное содержание углерода, водорода и кислорода в горючей массе по формулам [25]:

$$
\begin{aligned}
& C^{d a f}(\%)=K A_{C} /\left(A_{H}\left(H_{a t} / C_{a t}\right)+A_{O}\left(O_{a t} / C_{a t}\right)+A_{C}\right), \\
& H^{d a f}(\%)=K A_{H}\left(H_{a t} / C_{a t}\right) /\left(A_{H}\left(H_{a t} / C_{a t}\right)+A_{O}\left(O_{a t} / C_{a t}\right)+A_{C}\right), \\
& O^{d a f}(\%)=K A_{O}\left(O_{a t} / C_{a t}\right) /\left(A_{H}\left(H_{a t} / C_{a t}\right)+A_{O}\left(O_{a t} / C_{a t}\right)+A_{C}\right),
\end{aligned}
$$

где $K=100-N^{d a f}-S^{d a f}=97.4 \%$ - нормировочный коэффициент, учитывающий содержание серы и азота в углях и торфе (среднее содержание серы $S^{d a f}=0.8 \%$, азота $N^{d a f}=1.8 \%$ ), для древесной биомассы использовали нормировочный коэффициент 99.4, учитывающий содержание азота $N^{d a f}=0.6 \%$ и серы $S^{d a f}=0 \%$. Значения коэффициента $K$, содержание в горючей массе $S^{d a f}$ и $N^{d a f}$ были получены в работе [25] для твердых топлив с содержанием серы не более $2 \%$. $A_{C}$ - относительная атомная масса углерода, $A_{H}$ - относительная атомная масса водорода, $A_{O}-$ относительная атомная масса кислорода. 
Соотношение значений низшей теплоты сгорания твердых топлив $Q_{i}^{r}$, приведенных в литературе [18] и рассчитанных по формуле (2) на основе значений $\left(H_{a t} / C_{a t}\right)$ и $\left(O_{a t} / C_{a t}\right)$, определенных по разным вариантам, показано на рис. 7. Для пересчета элементного состава горючей массы на рабочую массу с использованием данных по содержанию общей влаги и зольности использовали формулы, приведенные в работе [16]. В табл. 3 отражен элементный состав, результаты технического анализа и низшая теплота сгорания углей разной степени метаморфизма с содержанием серы 2.1 $\div 8.4$ \% мас. по данным ВТИ, приведенных в работе [18]. Эти данные были использованы для оценки возможности применения разработанного метода для оценки низшей теплоты сгорания твердых топлив с содержанием серы в горючей массе более $2 \%$ мас.

Для варианта 1 среднеквадратичное отклонение при определении низшей теплоты сгорания в случае твердых топлив с содержанием серы не более $2 \%$ составило $3.4 \%$, для твердых топлив с содержанием серы $2.1 \div 8.4 \%-4.7 \%$. Для варианта 2 среднеквадратичное отклонение в случае твердых топлив с содержанием серы не более $2 \%$ составило $3.2 \%$, для твердых топлив с содержанием серы $2.1 \div 8.4 \%-5.6 \%$. Для варианта 3 среднеквадратичное отклонение в случае твердых топлив с содержанием серы не более $2 \%$ составило $3.0 \%$, для твердых топлив с содержанием серы $2.1 \div 8.4 \%-5.1 \%$. По полученным результатам видно, что применение та-

Таблица 3. Элементный состав, результаты технического анализа и низшая теплота сгорания углей разной

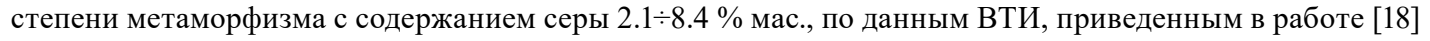

Table 3. Elemental composition, results of the technical analysis and net calorific values of coals of different metamorphism grade with sulfur content of $2.1 \div 8.4 \% \mathrm{wt}$. according to VTI data given in [18]

\begin{tabular}{|c|c|c|c|c|c|c|c|c|c|c|}
\hline Месторождение & 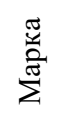 & $\stackrel{2}{2}$ & $\begin{array}{l}\partial^{\circ} \\
\nabla\end{array}$ & $\begin{array}{l}\partial^{\circ} \\
\text { 䙲 }\end{array}$ & $\frac{\partial^{\circ}}{\mathbb{S}^{\circ}}$ & $\begin{array}{l}\text { ठீ } \\
\text { ङू }\end{array}$ & $\begin{array}{l}\partial^{\circ} \\
\frac{8}{2}\end{array}$ & $\begin{array}{l}\partial^{\circ} \\
\text { 跑 }\end{array}$ & $\begin{array}{l}\partial^{\circ} \\
\stackrel{\Xi}{\Xi}\end{array}$ & ä \\
\hline Донецкий бассейн & A & 6.0 & 18.0 & 93.0 & 1.8 & 1.9 & 1.0 & 2.3 & 4.0 & 6110 \\
\hline Донецкий бассейн & $\mathrm{T}$ & 4.5 & 16.0 & 90.0 & 4.2 & 2.1 & 1.5 & 2.2 & 12.0 & 6600 \\
\hline Донецкий бассейн & $\mathrm{C}$ & 4.0 & 16.5 & 88.0 & 4.5 & 2.9 & 1.5 & 3.1 & 15.0 & 6580 \\
\hline Донецкий бассейн & K & 5.0 & 24.5 & 86.5 & 4.8 & 3.6 & 1.5 & 3.6 & 20.0 & 5780 \\
\hline Донецкий бассейн & Ж & 6.0 & 20.0 & 83.0 & 5.1 & 5.6 & 1.5 & 4.3 & 32.0 & 5980 \\
\hline Донецкий бассейн & $\Gamma$ & 8.0 & 16.0 & 80.5 & 5.4 & 8.3 & 1.5 & 4.3 & 39.0 & 5900 \\
\hline Кок-Янгак (Киргизия) & $\mathrm{CC}$ & 10.0 & 20.0 & 78.0 & 5.0 & 13.4 & 1.0 & 2.6 & 37.0 & 5130 \\
\hline Кизеловское (Урал) & $\mathrm{CC}$ & 6.0 & 30.0 & 78.0 & 5.2 & 6.7 & 1.3 & 8.4 & 40.0 & 5030 \\
\hline Тквибульское (Грузия) & $\Gamma$ & 11.0 & 25.0 & 77.5 & 5.7 & 13.2 & 1.5 & 2.1 & 41.0 & 4830 \\
\hline Донецкий бассейн & Д & 13.0 & 19.6 & 75.0 & 5.5 & 12.0 & 1.5 & 5.9 & 43.0 & 4840 \\
\hline Кизил-Кийское (Киргизия) & Б & 27.0 & 16.0 & 75.0 & 4.3 & 17.2 & 0.9 & 2.6 & 38.0 & 4010 \\
\hline Лежгеровское (Казахстан) & Б & 27.0 & 20.0 & 74.4 & 5.0 & 16.5 & 1.0 & 3.0 & 39.0 & 3870 \\
\hline Берчогурское (Казахстан) & $\Gamma$ & 6.0 & 50.0 & 73.0 & 6.5 & 13.2 & 1.4 & 5.9 & 42.0 & 3260 \\
\hline $\begin{array}{l}\text { Челябинское } \\
\text { (Урал) }\end{array}$ & Б & 17.0 & 32.0 & 72.0 & 5.2 & 19.0 & 1.7 & 2.1 & 43.0 & 3620 \\
\hline Звенигородское (Украина) & Б & 55.0 & 28.0 & 66.0 & 5.8 & 21.9 & 0.5 & 5.8 & 60.0 & 1660 \\
\hline Александрийское (Украина) & Б & 55.0 & 24.0 & 65.0 & 5.9 & 23.2 & 0.8 & 5.1 & 57.0 & 1780 \\
\hline
\end{tabular}




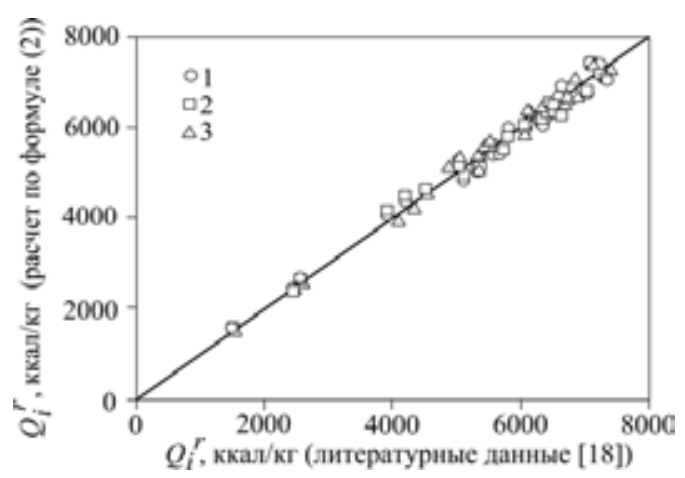

A

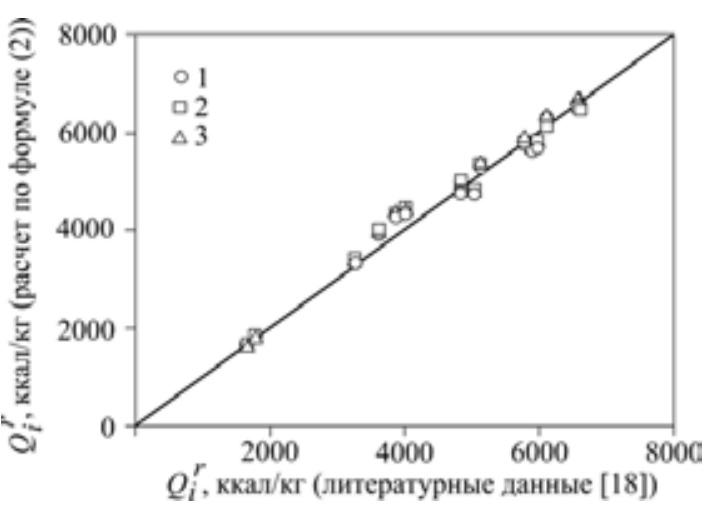

B

Рис. 7. Соотношение значений низшей теплоты сгорания твердых топлив $Q_{i}^{r}$, приведенных в литературе [18] и рассчитанных по формуле (2) на основе элементного состава горючей массы, определенного на основе отношений $\left(H_{a t} / C_{a t}\right)$ и $\left(O_{a t} / C_{a t}\right)$ по разным вариантам: 1 - вариант 1,2 - вариант 2,3 - вариант 3 ; $\mathbf{A}$ - для твердых топлив с содержанием серы не более $2 \%$ мас\%, В - для твердых топлив с содержанием серы $2.1 \div 8.4 \%$ мас.

Fig. 7. The ratio of net calorific values of solid fuels $Q_{i}^{r}$ presented in the literature [18] and calculated according to the formula (2) based on the elemental composition of the solid fuels combustible matter defined using relations $\left(H_{a t} / C_{a t}\right)$ and $\left(O_{a t} / C_{a t}\right)$ in different variants: 1 - variant 1,2 - variant 2, 3-variant 3 . A - for solid fuels with a sulfur content less than $2 \%$ wt., $\mathbf{B}$ - for solid fuels with a sulfur content of $2.1 \div 8.4 \% \mathrm{wt}$.

кого расчетного метода для определения низшей теплоты сгорания в случае твердых топлив с содержанием серы более $2 \%$ среднеквадратичное отклонение увеличивается. Одной из причин может быть перераспределение неучтенной серы по другим элементам, входящих в формулу Д.И. Менделеева.

В работе [6] показано, что при одном и том же содержании углерода выход летучих веществ может отличаться. Это связано с тем, что в процессе определения выхода летучих из минеральной массы удаляются диоксид углерода из карбонатов и гидратная влага минеральной массы, также происходит частичная потеря пиритной серы [26]. В случае большого содержания карбонатов необходимо учитывать их вклад в выход летучих веществ. Дополнительно возможно протекание каталитических процессов в присутствии соединений минеральной части твердых топлив при термическом воздействии на твердое топливо при определении выхода летучих веществ $[6,27]$. Например, в древесине содержатся растворимые в воде соли калия и натрия и нерастворимые соединения магния, кальция и др. [24]. В торфе также присутствуют соединения натрия калия, магния, кальция, железа, алюминия [28]. В углях присутствуют в основном соединения кремния, алюминия, железа, кальция, магния, титана, в виде микропримесей присутствует широкий спектр элементов, включая переходные металлы [29]. Поэтому можно предположить, что изменение соотношений элементов в минеральной части твердого топлива может повлиять на выход летучих веществ.

Таким образом, разработан расчетный метод оценки низшей теплоты сгорания твердых топлив. Схемы последовательностей определения необходимых параметров с использованием результатов технического анализа для различных вариантов имеют следующий вид: 
1) $\quad V^{\text {daf }} \rightarrow Z+Z_{O H} \rightarrow\left(H_{a t} / C_{a t}\right)$ и $\left(O_{a t} / C_{a t}\right) \rightarrow C^{d a f}, H^{d a f}, O^{\text {daf }}$ и среднее значение содержания серы в горючей массе $\rightarrow C^{r}, H^{r}, O^{r}, S^{r}$ с использованием результатов технического анализа $\left(W_{t}^{r}\right.$ и $\left.A^{d}\right) \rightarrow Q_{i}^{r}$;

2) $\quad V^{d a f} \rightarrow Z \rightarrow \alpha_{C} \rightarrow\left(H_{a t} / C_{a t}\right)$ и $\left(O_{a t} / C_{a t}\right) \rightarrow C^{d a f}, H^{d a f}, O^{d a f}$ и среднее значение содержания серы $\rightarrow C^{r}, H^{r}, O^{r}, S^{r} \rightarrow Q_{i}^{r}$;

3) $V^{\text {daf }} \rightarrow Z \rightarrow\left(H_{a t} / C_{a t}\right)$ и $\left(O_{a t} / C_{a t}\right) \rightarrow C^{d a f}, H^{d a f}, O^{d a f}$ и среднее значение содержания серы $\rightarrow$ $C^{r}, H^{r}, O^{r}, S^{r} \rightarrow Q_{i}^{r}$.

Полученные формулы применимы к таким твердым топливам, как древесина, торф, бурый уголь, каменный уголь, антрацит.

\section{Выводы}

Установлена взаимосвязь параметра $Z$, характеризующего конденсированность горючей массы твердых топлив, с выходом летучих веществ $V^{d a f}$. Показано, что параметр $Z$ позволяет оценить атомные отношения $\left(H_{a t} / C_{a t}\right)$ и $\left(O_{a t} / C_{a t}\right)$. На основе этого разработан расчетный метод определения низшей теплоты сгорания древесной биомассы, торфа, бурых углей, каменных углей и антрацита на основе данных технического анализа. Метод включает следующие стадии расчета: на основе данных по выходу летучих веществ $V^{d a f}$ определяется параметр $Z$, с использованием которого устанавливаются атомные отношения $\left(H_{a t} / C_{a t}\right)$ и $\left(O_{a t} / C_{a t}\right)$ и, соответственно, элементный состав горючей массы твердых топлив, на основе которого проводится оценка низшей теплоты сгорания твердых топлив с учетом содержания общей влаги и зольности. На основе такого метода проведена оценка низшей теплоты сгорания твердых топлив по формуле Д.И. Менделеева. Рассмотрено три варианта расчета атомных отношений $\left(H_{a t} / C_{a t}\right)$ и $\left(O_{a t} / C_{a t}\right)$. В зависимости от варианта расчета атомных отношений $\left(H_{a t} / C_{a t}\right)$ и $\left(O_{a t} / C_{a t}\right)$ среднеквадратичное отклонение низшей теплоты сгорания твердых топлив от литературных данных при содержании серы в горючей массе твердых топлив не более $2 \%$ мас. составило $3.0 \div 3.4 \%$. При содержании серы в горючей массе твердых топлив 2.1 $\div 8.4 \%$ мас. среднеквадратичное отклонение низшей теплоты сгорания твердых топлив от литературных данных составило 4.7-5.6 \%. Такой подход с использованием данных технического анализа для определения низшей теплоты сгорания твердых топлив может быть полезен в случае отсутствия данных по элементному составу и низшей теплоты сгорания твердого топлива, а также для контроля характеристик твердого топлива в котельных по месту.

Работа выполнена в рамках государственного задания ФГБУН ИК СО РАН (проект № 0303-2016-0012).

\section{Список литературы}

1. Боресков Г.К. Каталитические реакторы для промышленных химических процессов и сжигания топлива. Вестник АН СССР. 1980. № 12. С. 46-54. [Boreskov G.K. Catalytic reactors for industrial chemical processes and fuel combustion. Bulletin of the USSR Academy of Sciences. 1980. No. 12. P. 46-54. (In Russ.)]

2. Боресков Г.К., Левицкий Э.А. Пат. СССР 826798 МПК 6 F 23С 10/00. Способ сжигания топлив. БИ № 20, 1983. [Boreskov G.K., Levitsky E.A. Pat. USSR 826798 IPC 6 F 23C 10/00. A method of fuels combustion. BI No. 20, 1983. (In Russ.)]

$$
-106-
$$


3. Боресков Г.К. Гетерогенный катализ. М: Наука, 1986. 304 с. [Boreskov G.K. Heterogeneous catalysis. M: Nauka, 1986. 304 p. (In Russ.)]

4. Симонов А.Д., Федоров И.А., Дубинин Ю.В., Языков Н.А., Яковлев В.А., Пармон В.Н. Каталитические тепловые установки для промышленного теплоснабжения. Катализ в промышленности, 2012, № 3. С. 50-57. [Simonov A.D., Fedorov A.I., Dubinin Yu.V., Yazykov N.A., Yakovlev V.A., Parmon V.N. Catalytic thermal plants for industrial heating. Catalysis in industry, 2012, No. 3, P. 50-57. (In Russ.)]

5. Симонов А. Д., Языков Н.А., Афлятунов А.С., Федоров И.А., Яковлев В.А., Пармон В.Н. Опыт эксплуатации водогрейных котлов с каталитическим сжиганием жидкого и твердого топлива в псевдоожиженном слое. Альтернативная энергетика и экология. 2014. № 19(159). C. 70-85. [Simonov A.D., Yazykov N.A., Aflyatunov A.S., Fedorov I.A., Yakovlev V.A., Parmon V.N. The experience of operating boilers with catalytic combustion of liquid and solid fuels in fluidized bed. Alternative energy and ecology. 2014. No. 19(159). P. 70-85. (In Russ.)]

6. Русьянова Н.Д. Углехимия. М: Наука, 2000. 316 с. [Rusianova N.D. Coal chemistry. M: Nauka, 2000. 316 p. (In Russ.)]

7. Тайц Е.М., Андреева И.А. Методы анализа и испытания углей. М: Недра, 1983. 301 с. [Taits E.M., Andreeva I.A. Methods for analysis and testing of coal. M: Nedra, 1983. 301 p. (In Russ.)]

8. Менделеев Д.И. О теплоте горения углей и другого топлива. (1897). Соч. Т. XV. М: Издательство АН ССCP, 1949. С. 626-628. [Mendeleev D. I. About combustion heat of coals and other fuels. (1897). Op. T. XV. M: Izdatelsvo AN SSSR, 1949. P. 626-628. (In Russ.)]

9. Равич М.Б. Эффективность использования топлива. М: Наука, 1977. 344 с. [Ravich M.B. Fuel efficiency. M: Nauka, 1977. 344 p. (In Russ.)]

10. Ван-Кревелен Д.В., Шуер Ж. Наука об угле. М: Государственое научно-техническое издательство литературы по горному делу, 1960. 303 с. [Van Krevelen D.V., Schuyer J. Coal Science. M: State scientific-technical publishing house of literature on mining, 1960. 303 p. (In Russ.)]

11. Иванов И.А. Структурные параметры и принципы построения научной классификации твердых горючих ископаемых. Дис. ... канд. хим. наук. М: ФГУП Институт горючих ископаемых. Москва, 2004. 105 с. [Ivanov I.A. Structural parameters and principles of the scientific classification of solid fuels. Dis. kand. chem. sciences. M: FSUE Institute of fossil fuels. Moscow, 2004. 105 p. (In Russ.)]

12. Гюльмалиев А.М., Головин Г.С., Гладун Т.Г., Скопенко С.М. Обобщенная модель структуры органической массы углей. Химия твердого топлива. 1994. № 4-5. С. 14-27. [Gulmaliyev A.M., Golovin G.S., Gladun T.G., Skopenko S.M. Generalized model of the structure of the coals organic mass. Solid fuel chemistry. 1994. No. 4-5. P. 14-27. (In Russ.)]

13. Гюльмалиев А.М, Головин Г.С., Гладун Т.Г. Теоретические основы химии угля. М: Издво МГГУ, 2003. 556 с. [Gulmaliyev A.M, Golovin G.S., Gladun, T.G. Theoretical grounds of coal chemistry. M: Publishing house of Moscow state mining university, 2003. 556 p. (In Russ.)]

14. Школлер М.Б. Полукоксование каменных и бурых углей. Новокузнецк: Инженерная академия России. Кузбасский филиал, 2001. 232 с. [Shkoller M.B. Semicoking of coal and lignite. Novokuznetsk: Engineering Academy of Russia. Kuzbass branch, 2001. 232 p. (In Russ.)]

$$
-107 \text { - }
$$


15. Лазаров Л., Ангелова Г. Структура и реакции углей. София: Издательство Болгарской Академии наук. 1990. 232 с. [Lazarov L., Angelova G. Structure and reactions of coals. Sofia: Publishing house of the Bulgarian Academy of Sciences, 1990. 232 p. (In Russ.)]

16. Химия и переработка угля. Под редакцией д-ра хим. наук, профессора Липовича В.Г. М.: Химия, 1988. 336 c. [Chemistry and processing of coal. Under the editorship of Dr. chem. sciences, Professor V.G. Lipovich M: Khimiya, 1988. 336. (In Russ.)]

17. Соболева Е.В., Гусева А.Н. Химия горючих ископаемых. М: Издательство Московского университета, 2010. 312 с. [Soboleva E.V., Guseva A.N. Chemistry of fossil fuels. M: Publishing house of Moscow University, 2010. 312 p. (In Russ.)]

18. Мамыкин П.С., Левченко Т.В., Стрелов К.Х. Печи и сушила огнеупорных заводов. Свердловск: Государственное научно-техническое издательство литературы по черной и цветной металлургии, 1968. 471 с. [Mamykin P.S., Levchenko T.V., Strelov K.H. Kilns and driers of refractory plants. Sverdlovsk: State scientific and technical publishing house of literature on ferrous and nonferrous metallurgy, 1968. 471 p. (In Russ.)]

19. Гюльмалиев А.М., Гагарин С.Г. Молекулярное моделирование структуры и свойства органической массы углей. Химия твердого топлива. 2010. № 3. С. 16-25. [Gulmaliyev M.A., Gagarin S.G. Molecular modeling of structure and properties of organic mass of coal. Solid fuel chemistry. 2010. No. 3. P. 16-25. (In Russ.)]

20. Гюльмалиев А.М, Иванов И.А., Головин Г.С. Структурно-химические показатели и классификационные характеристики горючих ископаемых. Химия твердого топлива. 2004. № 1. C. 3-17. [Gulmaliyev A., Ivanov I.A., Golovin G.S. Structural-chemical characteristics and classification characteristics of fossil fuels. Solid fuel chemistry. 2004. No. 1. P. 3-17. (In Russ.)]

21. Бычев М.И. Расчет основных связей углерода в углях различных стадий метамофизма. Химия твердого топлива. 2012. № 2. С. 10-16. [Bichev M.I. Calculation of the basic bonds of carbon in coals of different stages of metamorphism. Solid fuel chemistry. 2012. No. 2. P. 10-16. (In Russ.)]

22. Долгушин И.А. Исследование и совершенствование ТЭС с котлом ЦКС для повышения эффективности и улучшения экологических показателей. Дисс. канд. техн. наук. Москва, 2014. 166 c. [Dolgushin I. A. Study and improvement of thermal power plant with CFB boiler to increase efficiency and improve environmental performance. Diss. cand. tech. sciences, Moscow, 2014. 166 p. (In Russ.)]

23. Кабо Г.Я., Блохин А.В., Симирский В.В., Ивашкевич О.А. Использование растительной биомассы для производства различных видов топлива в республике Беларусь. Химические проблемы создания новых материалов и технологий. 2008. Выпуск 3. Минск. Электронная библиотека БГУ. [Kabo G.J., Blokhin A.V., simirsky V.V., Ivashkevich O.A. the Use of plant biomass for the production of various fuels in the Republic Belarus. Chemical problems of creating new materials and technologies. 2008. Issue 3. Minsk. Electronic library of BGU. (In Russ.)] http://elib. bsu.by/handle/123456789/13331

24. Терентьева Э.П., Удовенко Н.К., Павлова Е.А. Химия древесины, целлюлозы и синтетических полимеров: учебное пособие. Часть 2. СПб: СПбТУРП, 2015. 83 с. [Terentieva Е.P., Udovenko N.To., Pavlova E.A. Chemistry of wood, cellulose and synthetic polymers: training manual. Part 2. SPb: SPbTUPP, 2015. 83 p. (In Russ.)] 
25. Языков Н.А., Симонов А.Д., Яковлев В.А. Оценка низшей теплоты сгорания растительной биомассы, торфа и ископаемых углей на основе технического анализа. Химия в интересах устойчивого развития 2017. T. 25 (4). C. 465-471. [Yazykov N.A., Simonov A.D., Yakovlev V.A. Evaluation of the net calorific value of plant biomass, peat and fossil coal on the basis of technical analysis. Chemistry for Sustainable Development. 2017. Vol. 25 (4). P. 465-471. (In Russ.)]

26. ГОСТ Р 54245-2010. Топливо твердое минеральное. Пересчет результатов анализа на различные состояния топлива. М: ФГУП Институт горючих имкопаемых. 14 с. [GOST R 542452010. Solid mineral fuel. Recalculation of analysis results for various States of fuel. M: FSUE Institute of fossil fuels. 14 p. (In Russ.)]

27. Кузнецов Б.Н. Катализ химических превращений угля и биомассы. Новосибирск: Наука. Сибирское отделение, 1990. 302 c. [Kuznetsov B.N. Catalysis of chemical transformations of coal and biomass. Novosibirsk: Science. Siberian branch, 1990. 302 p. (In Russ.)]

28. Смирнов В.И. Практическое руководство по организации добычи фрезерного торфа: учебное пособие. 1-е изд. Тверь: ТГТУ, 2007. 392 с. [Smirnov V.I. Practical guide to the organization of production of milled peat: training manual. 1st ed. Tver: TSTU, 2007. 392 p. (In Russ.)]

29. Зырянов В.В., Зырянов Д.В. Зола уноса - техногенное сырье. М: ООО «ИПЦ Маска», 2009. 320 c. [Zyryanov V.V., Zyryanov D.V., Fly ash - technogenic raw material. M: LLC "IPC Mask", 2009. 320 p. (In Russ.)] 